\title{
Seletividade de Amonio-Glufosinate Isolado e em Mistura com Pyrithiobac-Sodium em Algodoeiro Transgênico LL ${ }^{\circledR 1}$
}

\author{
Selectivity of Ammonium-Glufosinate Applied Alone or in Mixture with Pyrithiobac Sodium in \\ Transgenic LL ${ }^{\circledR}$ Cotton
}
BRAZ, G.B.P. ${ }^{2}$, OLIVEIRA JR, R.S. ${ }^{3}$, CONSTANTIN, J. ${ }^{3}$, RAIMONDI, M.A. ${ }^{2}$, FRANCHINI, L.H.M. ${ }^{2}$, BIFFE, D.F. ${ }^{3}$, ARANTES, J.G.Z. ${ }^{2}$ e TAKANO, H.K. ${ }^{4}$

\begin{abstract}
RESUMO - Com a recente introdução no Brasil de variedades transgênicas de algodoeiro que apresentam resistência ao amonio-glufosinate $\left(\mathrm{LL}^{\circledR}\right)$, há escassez de informações tanto a respeito da seletividade de reaplicações desse herbicida, quanto no que se refere a misturas com outros herbicidas. Objetivou-se no presente trabalho avaliar a seletividade de aplicações sequenciais de amonio-glufosinate isolado e em associação com pyrithiobac-sodium em algodão transgênico $L_{L}{ }^{\circledR}$. Dessa forma, foi instalado um experimento em delineamento de blocos casualizados em arranjo fatorial $(3 \times 3)+1$, empregando-se oito repetições. O primeiro fator correspondeu à aplicação dos tratamentos amonio-glufosinate (500 $\left.\mathrm{g} \mathrm{ha}^{-1}\right)$ e amonio-glufosinate + pyrithiobac-sodium $\left(500+42 \mathrm{~g} \mathrm{ha}^{-1}\right.$ e $\left.500+56 \mathrm{~g} \mathrm{ha}^{-1}\right)$. O segundo fator foi o número de aplicações sequenciais em pós-emergência do algodoeiro (uma, duas ou três). O tratamento adicional foi composto por testemunha sem aplicação de herbicida. A associação do pyrithiobacsodium ao amonio-glufosinate causou maiores niveis de fitointoxicação inicial, embora não tenham havido mais sintomas duas semanas após as aplicações. A qualidade de fibra do algodoeiro não foi influenciada por nenhum dos tratamentos herbicidas. O amonio-glufosinate isolado foi seletivo para o algodão $L^{\circledR}{ }^{\circledR}$ em até três aplicações em pós-emergência. O algodoeiro apresentou ainda tolerância a uma aplicação da mistura de amonio-glufosinate + pyrithiobacsodium, e não se observou qualquer efeito negativo sobre a produtividade de algodão em caroço.
\end{abstract}

Palavras-chave: Gossypium hirsutum, fitointoxicação, inibidor da glutamina sintetase, inibidor de ALS, mistura em tanque.

\begin{abstract}
Due to the recent introduction of transgenic cotton varities with resistance to ammonium-glufosinate $\left(L L^{\circledR}\right)$ in Brazil, there is a lack of information related both to the selectivity of sequential reapplications of ammonium-glufosinate and to tank mixture with other herbicides. This work aimed to evaluate the selectivity of sequential applications of ammonium-glufosinate isolated or in associations with pyrithiobac-sodium in $L L^{\circledR}$ cotton. A field experiment was installed in a randomized block design with eight replicates. Treatments were arranged in a factorial scheme (3x3)+1. The first factor consisted of herbicide treatments as follows: ammonium-glufosinate (500 $\mathrm{g} \mathrm{ha} \mathrm{h}^{-1}$ ), ammoniumglufosinate + pyrithiobac-sodium $\left(500+42 \mathrm{~g} \mathrm{ha}^{-1}\right.$ and $\left.500+56 \mathrm{~g} \mathrm{ha}^{-1}\right)$. The second factor was the number of sequential post-emergence applications (one, two, or three), and the additional treatment was a non-applied check. All treatments were manually kept free of weeds throughout the crop cycle. Associating pyrithiobac-sodium to ammonium-glufosinate increased initial crop injury although no significant injury differences were found two weeks after application. Cotton fiber quality was not affected by any herbicidal treatment. Use of isolated ammonium-glufosinate was selective to $L L^{\circledR}$ cotton up to three sequential post-emergence applications. $L L^{\circledR}$ Cotton yield was also sustained after one application of ammonium-glufosinate + pyrithiobac-sodium, with no effects on crop yield.
\end{abstract}

Keywords: Gossypium hirsutum, crop injury, GS inhibitor, ALS-inhibitor, tank mixture.

Recebido para publicação em 27.11.2011 e aprovado em 25.4.2012.

2 Engo-Agro-, M.Sc., Aluno do Programa de Pós-Graduação em Agronomia, Universidade Estadual de Maringá - UEM, $87020-900$ Maringá-PR, Brasil, <guilhermebrag@gmail.com>; ${ }^{3}$ Prof. Dr., Dep. de Agronomia, DAG/UEM; ${ }^{4}$ Acadêmico da Faculdade de Agronomia, UEM.

Planta Daninha, Viçosa-MG, v. 30, n. 4, p. 853-860, 2012 


\section{INTRODUÇÃO}

Ao longo das décadas, a cotonicultura brasileira passou por grandes dificuldades em seu sistema de produção e comercialização. Inicialmente, a entrada de uma nova praga, o bicudo do algodoeiro, dizimou plantações por todo o País, fazendo com que houvesse redução na produção dessa cultura. Posteriormente, na década de 1990, ocorreu o processo de abertura das fronteiras comerciais brasileiras, que proporcionou a entrada de produtos estrangeiros com preços mais competitivos, diminuindo a área cultivada dessa cultura. $\mathrm{Na}$ última década houve revitalização na importância do algodoeiro, que atualmente consiste na espécie mais semeada no Brasil, com o objetivo de produção de fibras para as indústrias têxteis (Constantin et al., 2007).

Entre os fatores que contribuem negativamente para o rendimento do algodão, a interferência imposta pelas plantas daninhas consiste em um dos mais danosos, pois acarreta grandes prejuízos à produção quando não manejadas (Dan et al., 2011). As reduções de rendimento provocadas pela interferência das plantas daninhas no algodoeiro podem variar de 82 a 98\% (Freitas et al., 2002).

O potencial de interferência que a comunidade infestante apresenta sobre o rendimento do algodão é elevado. Entretanto, a utilização de herbicidas nessa cultura consiste em excelente prática de manejo, por apresentar grande eficácia na maioria dos casos (Branson et al., 2005).

O número de herbicidas disponíveis para controle de espécies dicotiledôneas no algodoeiro em pós-emergência em área total é restrito, criando uma constante necessidade de pesquisas que busquem novas moléculas que sejam seletivas para essa cultura nessa modalidade de aplicação (Miller et al., 2003). A partir dos anos 90, as pesquisas sobre a seletividade de herbicidas aplicados em pós-emergência no algodoeiro se estenderam para algumas variedades transgênicas, as quais apresentavam tolerância/resistência a alguns produtos, como glyphosate, bromoxynil e amonio-glufosinate (Troxler et al., 2002; Thomas et al., 2004).

O amonio-glufosinate apresenta elevada seletividade ao algodão transgênico $L^{\circledR}{ }^{\circledR}$
("Liberty Link"), não se observando alterações morfofisiológicas nas plantas tratadas com esse herbicida (Blair-Kerth et al., 2001). A resistência apresentada pelo algodoeiro geneticamente modificado a esse herbicida ocorre em função de elevada eficiência na metabolização do amonio-glufosinate; plantas transgênicas são capazes de metabolizar $70 \%$ do herbicida absorvido num periodo de 72 horas após a sua aplicação, ao passo que as não transgênicas metabolizam apenas $16 \%$ (Everman et al., 2009).

O amonio-glufosinate apresenta amplo espectro de controle de plantas daninhas, porém a atividade residual desse herbicida no solo é minima. Aparentemente, a falta de atividade residual no solo parece estar ligada ao fato de que o amonio-glufosinate é pouco sorvido ao solo e rapidamente degradado pelos microrganismos (Mahan et al., 2006). Entretanto, a mistura de amonio-glufosinate com produtos que apresentem efeito residual pode suprir essa carência, ampliando o espectro de controle e reduzindo a emergência de novos fluxos de plantas daninhas (Koger et al., 2007).

Nesse contexto, o pyrithiobac-sodium apresenta-se como boa alternativa para associação com o amonio-glufosinate, por ser um herbicida seletivo ao algodão em pós-emergência e apresentar um período de meia-vida de 62 dias no campo e 43 em casa de vegetação, o que é um indicativo da persistência que esse herbicida possui no solo (Webster \& Shaw, 1997).

Em razão da recente introdução, no Brasil, de cultivares transgênicos de algodoeiro que apresentam resistência ao amonioglufosinate $\left(\mathrm{LL}^{\circledR}\right)$, há escassez de informações tanto a respeito da seletividade de reaplicações de amonio-glufosinate, visando ao controle de novos fluxos de plantas daninhas, quanto a respeito de misturas com outros herbicidas para obtenção de controle residual para essa cultura. A partir dessas carências, objetivouse neste trabalho avaliar a seletividade de aplicações sequenciais de amonio-glufosinate isolado e em associação com pyrithiobacsodium em algodão transgênico $L^{\circledR}$.

\section{MATERIAL E MÉTODOS}

O experimento foi instalado na Fazenda Indaiá (S 18 '41'50,06' e W 052'55'12,9', a 
$844 \mathrm{~m}$ de altitude), localizada no município de Chapadão do Sul - MS. O período de condução do experimento foi de dezembro de 2009 a julho de 2010.

Antecedendo a instalação do ensaio, procedeu-se à coleta de solo dentro da área experimental para a realização da análise físicoquímica, obtendo-se os seguintes valores: $\mathrm{pH}$ $\left(\mathrm{CaCl}_{2}\right)$ de 5,$3 ; 4,3 \mathrm{cmol}_{\mathrm{c}}$ de $\mathrm{H}^{+}+\mathrm{Al}^{+3} \mathrm{dm}^{3}$ de solo; $3,7 \mathrm{cmol}_{\mathrm{c}} \mathrm{dm}^{-3} \mathrm{de} \mathrm{Ca}^{+2} ; 0,9 \mathrm{cmol}_{\mathrm{c}} \mathrm{dm}^{-3} \mathrm{de}$ $\mathrm{Mg}^{+2} ; 0,3 \mathrm{cmol}_{\mathrm{c}} \mathrm{dm}^{-3}$ de $\mathrm{K}^{+} ; 10,3 \mathrm{mg} \mathrm{dm}^{-3}$ de P; $38,3 \mathrm{~g} \mathrm{dm}^{-3}$ de mat. org.; $24 \%$ de areia; $13 \%$ de silte; e $63 \%$ de argila (textura muito argilosa). $\mathrm{O}$ solo da área experimental foi identificado como Latossolo Vermelho.

O manejo de plantas daninhas antes da semeadura do algodoeiro foi realizado por meio de duas dessecações: a primeira foi aos 12 dias antes da semeadura com glyphosate (1.920 $\mathrm{g} \mathrm{ha}^{-1}$ ), e a segunda, um dia antes da semeadura, utilizando-se paraquat (400 $\left.\mathrm{g} \mathrm{ha}^{-1}\right)$.

A adubação de plantio consistiu na aplicação de $300 \mathrm{~kg}^{-1}$ de superfostato simples, sendo realizadas duas coberturas a lanço com $200+250 \mathrm{~kg} \mathrm{ha}^{-1}$ de cloreto de potássio + sulfato de amonio. A semeadura do algodão foi no dia 23/12/2009, utilizando a variedade Fiber Max 966 LL $^{\circledR}$. O espaçamento adotado foi de $0,9 \mathrm{~m}$ entre linhas, com densidade de 8,5 sementes $\mathrm{m}^{-1}$. Aos 85 dias após a emergência (DAE), foi realizada a primeira aplicação do regulador de crescimento cloreto de mepiquat 1,0 L p.c. ha- ${ }^{-1}\left(\mathrm{Pix}^{\circledR}\right)$, sendo essa dose parcelada em duas vezes.

O delineamento experimental foi de blocos casualizados, com oito repetições, sendo os tratamentos dispostos em arranjo fatorial $(3 \times 3)+1$. O primeiro fator correspondeu à aplicação de amonio-glufosinate $\left(500 \mathrm{~g} \mathrm{ha}^{-1}\right)$, amonio-glufosinate + pyrithiobac-sodium (500 + $42 \mathrm{~g} \mathrm{ha}^{-1}$ ) e amonio-glufosinate + pyrithiobacsodium $\left(500+56 \mathrm{~g} \mathrm{ha}^{-1}\right)$. O segundo fator foi o número de aplicações sequenciais em pósemergência do algodoeiro (uma, duas ou três). Além disso, um tratamento adicional composto por testemunha sem aplicação de herbicida foi incluído.

Cada unidade experimental foi composta por seis linhas de algodoeiro, com seis metros de comprimento. Foi desconsiderado, nas avaliações, 0,5 $\mathrm{m}$ de cada extremidade das parcelas, totalizando uma área útil de $18,0 \mathrm{~m}^{2}$. Os dados de precipitação plluvial durante os meses em que o ensaio foi conduzido estão apresentados na Figura 1.

Todos os tratamentos foram capinados durante todo o ciclo do algodoeiro, a fim de eliminar o efeito da matocompetição sobre a produtividade da cultura, deixando as plantas expostas apenas ao efeito dos herbicidas. As aplicações foram feitas com um pulverizador costal à base de $\mathrm{CO}_{2}$, munido de pontas XR110.02, mantido à pressão de $35 \mathrm{lb} \mathrm{pol}{ }^{-2}$, resultando em volume de calda equivalente a $200 \mathrm{~L} \mathrm{ha}^{-1}$. Os dados de condições climáticas e estádio do algodoeiro no momento das aplicações encontram-se na Tabela 1 .

Foram realizadas avaliações de fitointoxicação das plantas de algodoeiro aos 7 e 14 dias após cada uma das aplicações sequenciais dos

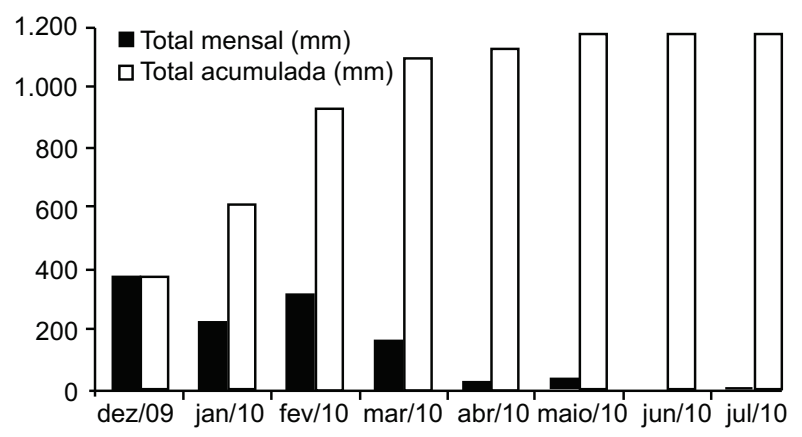

Figura 1 - Precipitação pluvial mensal e acumulada ( $\mathrm{mm}$ ) durante os meses de condução do ensaio de seletividade de herbicidas em pós-emergência no algodão $\mathrm{LL}^{\circledR}$. Chapadão do Sul-MS, 2010.

Tabela 1 - Condições climáticas e estádio de desenvolvimento da cultura por ocasião das diferentes aplicações sequenciais em pós-emergência no algodão $L^{\circledR}{ }^{\circledR}$. Chapadão do Sul-MS, 2010

\begin{tabular}{|l|c|c|c|}
\hline & $\begin{array}{c}1^{\text {a }} \text { aplicação } \\
(12 / 1 / 2010)\end{array}$ & $\begin{array}{c}2^{\text {a }} \text { aplicação } \\
(26 / 1 / 2010)\end{array}$ & $\begin{array}{c}3^{\text {a }} \text { aplicação } \\
(20 / 2 / 2010)\end{array}$ \\
\hline Umidade relativa $(\%)$ & 82 & 75 & 72 \\
\hline Temperatura $\left({ }^{\circ} \mathrm{C}\right)$ & 26 & 23 & 24 \\
\hline Vel. do vento $\left(\mathrm{km} \mathrm{h}^{-1}\right)$ & 2 & 1,7 & 2 \\
\hline Alt. de plantas $(\mathrm{cm})$ & 18 & 28 & 50 \\
\hline Estádio fenológico* & $\mathrm{V} 6$ & $\mathrm{~V} 8$ & $\mathrm{~B} 1$ \\
\hline Dias após a emergência & 10 & 24 & 49 \\
\hline
\end{tabular}

* Fonte: Marur \& Ruano (2001). V6 - quatro folhas verdadeiras expandidas; V8 - seis folhas verdadeiras expandidas; B1 - primeiro botão floral visível.

Planta Daninha, Viçosa-MG, v. 30, n. 4, p. 853-860, 2012 
herbicidas (DAA), por meio de escala visual (1-9, em que 1 significa ausência de sintomas e 9 a morte total das plantas) (EWRC, 1964). Realizou-se também uma avaliação de altura de plantas aos 80 dias após a emergência (DAE), antes da aplicação do regulador de crescimento e 31 dias após a terceira aplicação de herbicidas. Para esta avaliação, mediu-se a altura da planta desde o nivel do solo até a inserção da última folha completamente expandida.

Aos 100 DAE, avaliou-se a incidência de luz na entrelinha do algodoeiro, por meio de luxímetro (Minipa, modelo MLM-1011), realizando-se duas amostragens por unidade experimental.

Para determinar a produtividade de cada tratamento, procedeu-se à colheita da área útil (1/07/2010), e os valores foram apresentados em rendimento de algodão em caroço, em arrobas por hectare, efetuando-se desconto de umidade igual a $13 \%$. Após a colheita manual de todas as plantas da área útil das parcelas, foram realizadas análises da qualidade da fibra produzida, sendo avaliados: o indice Micronaire, que representa o complexo finura + maturidade, determinado no aparelho Fibronaire, o qual revela a proporção do fluxo de ar que atravessa uma amostra de fibra de 3,24 g, sob pressão constante; e a maturidade, dada em porcentagem, que corresponde ao índice médio fornecido pelo fibrógrafo, segundo método proposto por Sabino et al. (1980).

Os dados foram submetidos à análise de variância. Quando houve significância entre os fatores ou entre os niveis de cada fator, aplicou-se o teste de Tukey a 5\% de probabilidade. A comparação entre os tratamentos e a testemunha capinada foi feita pelo teste de Dunnett $(\mathrm{p} \leq 5 \%)$.

\section{RESULTADOS E DISCUSSÃO}

A aplicação de amonio-glufosinate isolado não causou injúrias visiveis nas plantas de algodão aos $7 \mathrm{DAA}$, independentemente do número de aplicações realizadas em pósemergência (Tabela 2). Tendência semelhante foi descrita anteriormente na literatura no que diz respeito à tolerância do algodão $L^{\circledR}{ }^{\circledR}$ ao amonio-glufosinate isolado (Blair-Kerth et al., 2001). Essa capacidade do algodão transgênico, resistente ao amonio-glufosinate, de tolerar mais de uma aplicação desse herbicida tem sido atribuída à rápida metabolização em compostos inativos no interior das plantas (Everman et al., 2009).

Quando se adicionou pyrithiobac-sodium ao amonio-glufosinate, os sintomas de fitointoxicação inicial (7 DAA) foram mais severos, sobretudo nas plantas que receberam maiores doses de pyrithiobac-sodium (56 $\left.\mathrm{g} \mathrm{ha}^{-1}\right)$. Nesses tratamentos, as plantas apresentaram menor porte, e em algumas partes do limbo foliar foi verificado encarquilhamento, arroxeamento e necrose (nota 6, pela escala EWRC, 1964).

Observando os niveis de injúria aos 7 DAA, constata-se que a fitointoxicação do algodoeiro é maior após a primeira aplicação do que após a segunda ou terceira, quando é utilizada a mistura de amonio-glufosinate e pyrithiobacsodium (Tabela 2). Nas avaliações das reaplicações, independentemente da dose de pyrithiobac-sodium utilizada, verificou-se clorose mais pronunciada apenas próximo às nervuras das folhas novas, além de leve encarquilhamento e ligeira redução de porte (nota 3, pela escala EWRC, 1964).

A menor sensibilidade do algodoeiro às aplicações sequenciais da mistura entre amonio-glufosinate e pyrithiobac-sodium pode estar relacionada ao estádio mais avançado em que a cultura se encontrava no momento das aplicações. Em geral, as plantas em estádios mais desenvolvidos de formação apresentam alterações nas características morfofisiológicas, que lhe conferem maior

Tabela 2 - Resultados das avaliações visuais de fitointoxicação (EWRC, 1964) realizadas aos 7 e 14 DAA de amonioglufosinate isolado e em associação com pyrithiobac-sodium em pós-emergência, em algodão transgênico. Chapadão do Sul-MS, 2010

\begin{tabular}{|l|c|c|c|c|c|c|}
\hline \multirow{2}{*}{ Tratamento } & \multicolumn{6}{|c|}{ Número de aplicações } \\
\cline { 2 - 8 } & \multicolumn{3}{|c|}{7 DAA } & \multicolumn{3}{c|}{ 14 DAA } \\
\cline { 2 - 7 } & 1 & 2 & 3 & 1 & 2 & 3 \\
\hline Gluf. $\left(500 \mathrm{~g} \mathrm{ha}^{-1}\right)$ & 1 & 1 & 1 & 1 & 1 & 1 \\
\hline Gluf. + pyri $\left(500+42 \mathrm{~g} \mathrm{ha}^{-1}\right)$ & 5 & 3 & 3 & 1 & 1 & 1 \\
\hline Gluf. + pyri $\left(500+56 \mathrm{~g} \mathrm{ha}^{-1}\right)$ & 6 & 3 & 3 & 1 & 1 & 1 \\
\hline Testemunha capinada & \multicolumn{3}{|c|}{1} & \multicolumn{5}{c|}{1} \\
\hline
\end{tabular}

Gluf. (amonio-glufosinate); pyri. (pyrithiobac-sodium). 
tolerância a herbicidas. Em espécies como algodão, soja e milho, a maior deposição de cutícula sobre o limbo foliar e a maior capacidade de degradação dos herbicidas são fatores que têm sido usados para explicar o aumento da tolerância a herbicidas em estádios de desenvolvimento mais avançados (Souza et al., 2001; Cavalieri et al., 2008).

Quando se realizaram as avaliações de fitointoxicação aos 14 DAA, nenhuma das plantas apresentava injúrias visiveis provocadas pela aplicação dos diferentes tratamentos (Tabela 2), o que indica que, mesmo quando ocorreram injúrias iniciais significativas, houve rápida recuperação das plantas. Resultados de trabalho anteriormente realizado demonstraram semelhante comportamento do algodão com relação à rápida recuperação dos sintomas provocados pela aplicação de pyrithiobacsodium, na dose de $140 \mathrm{~g} \mathrm{ha}^{-1}$ (Almeida $\&$ Leite, 1999). Conhecendo os possiveis efeitos da adoção de misturas entre herbicidas, a comparação com os dados deste trabalho é importante, já que a dose de pyrithiobac-sodium utilizada foi 2,5 vezes maior. Observa-se que, independentemente do número de aplicações, a adição de pyrithiobac-sodium ao amonio-glufosinate causa aumento no nível de injúria inicial observada no algodoeiro, sem, no entanto, refletir em qualquer diferença aos 14 DAA.

Na Tabela 3 são apresentados os valores de altura das plantas de algodão aos 80 DAE. A primeira constatação que pode ser feita é o

Tabela 3 - Altura (cm) das plantas de algodão aos 80 dias após a emergência, em função do número de aplicações de amonioglufosinate isolado e em associação com pyrithiobac-sodium. Chapadão do Sul-MS, 2010

\begin{tabular}{|l|c|c|c|}
\hline \multirow{2}{*}{\multicolumn{1}{|c|}{ Tratamento }} & \multicolumn{3}{|c|}{ Número de aplicações } \\
\cline { 2 - 4 } & 1 & 2 & 3 \\
\hline Gluf. $\left(500 \mathrm{~g} \mathrm{ha}^{-1}\right)$ & $102,95 * \mathrm{Aa}$ & $100,77 * \mathrm{Aa}$ & $95,45 * \mathrm{Ba}$ \\
\hline Gluf. + pyri $\left(500+42 \mathrm{~g} \mathrm{ha}^{-1}\right)$ & $96,42 * \mathrm{Ab}$ & $92,50 * \mathrm{Bb}$ & $91,40 * \mathrm{Bb}$ \\
\hline Gluf. + pyri $\left(500+56 \mathrm{~g} \mathrm{ha}^{-1}\right)$ & $93,72 * \mathrm{Ab}$ & $94,12 * \mathrm{Ab}$ & $86,82 * \mathrm{Bc}$ \\
\hline Testemunha capinada & \multicolumn{3}{|c}{108,57} \\
\hline CV $(\%)$ & 3,13 \\
\hline DMStratamentos & \multicolumn{3}{|c}{$3,-3$} \\
\hline DMStestemunha & \multicolumn{3}{|c}{4,24} \\
\hline
\end{tabular}

Gluf. (amonio-glufosinate); pyri. (pyrithiobac-sodium); * Diferem da testemunha pelo teste de Dunnett $(\mathrm{p} \leq 0,05)$; Médias seguidas por letras maiúsculas distintas, na linha, e por letras minúsculas, na coluna, diferem pelo teste de Tukey $(\mathrm{p} \leq 0,05)$. fato de que, em maior ou menor grau, todos os tratamentos causaram redução na taxa de crescimento das plantas, fazendo com que estas apresentassem altura inferior à da testemunha sem herbicida. Por mais que um herbicida apresente-se seletivo para uma espécie vegetal, a sua utilização exerce alterações na fisiologia da planta, fazendo com que esta necessite expressar genes que conferem tolerância aos produtos. Muitas vezes, a expressão desses genes implica elevados gastos metabólicos, o que faz com que características morfológicas das plantas possam ser transitórias ou definitivamente afetadas (Monquero, 2005).

A adoção de uma terceira aplicação de amonio-glufosinate alterou o crescimento das plantas de algodão, quando comparada à aplicação do herbicida uma ou duas vezes em pós-emergência. Os resultados demonstram que, apesar da alta tolerância do algodão ao amonio-glufosinate, o gasto metabólico da planta para a metabolização desse herbicida implica menor alocação de recursos destinados ao crescimento.

Quando se compara a aplicação do amonioglufosinate isolado, independentemente do número de aplicações, com os tratamentos com a associação desse herbicida ao pyrithiobacsodium, verifica-se redução média de altura de $7 \%$. Apesar de esse valor ser relativamente baixo, a redução na altura das plantas de algodoeiro pode implicar menor altura do solo até os primeiros capulhos formados, o que eventualmente pode ocasionar maiores perdas na colheita.

A incidência de luz nas entrelinhas das culturas pode ser um indicativo do efeito de determinado herbicida na extensão do dossel da cultura. Espera-se que plantas que apresentem maior nivel de injúria causada pela aplicação do herbicida tenham também menor desenvolvimento do dossel, o que, por sua vez, implica menor cobertura do solo e, consequentemente, maior incidência de luz nas entrelinhas. Os resultados da avaliação de incidência de luz nas entrelinhas do algodão estão registrados na Tabela 4.

Apesar de nenhum dos tratamentos ter diferido da testemunha, nota-se claramente que houve correlação entre os níveis de 
fitointoxicação provocados e os valores de incidência de luz na entrelinha do algodoeiro, observando-se diferenças entre os manejos empregados em pós-emergência. O amonioglufosinate isolado, independentemente do número de aplicações, apresentou valores muito próximos aos observados na testemunha, demonstrando que esse herbicida, apesar de ter causado redução de altura, provavelmente não alterou a cobertura do solo pelas plantas tratadas com ele. Esses resultados são importantes quando se pensa no manejo cultural, pois conferem ao algodoeiro a capacidade de exercer sombreamento sobre plantas daninhas já emergidas, causando redução na taxa de crescimento destas e diminuição na emergência de novos fluxos de infestantes (Lee et al., 2009).

De maneira semelhante aos resultados encontrados nas avaliações de altura de plantas, a incidência de luz nas entrelinhas foi mais afetada quando se empregou a mistura entre amonio-glufosinate e pyrithiobacsodium. A aplicação de pyrithiobac-sodium junto com amonio-glufosinate permitiu, em média, a passagem de $27 \%$ de luminosidade a mais em relação ao amonio-glufosinate isolado, demonstrando a redução no dossel do algodoeiro que essa mistura exerceu.

As alterações na morfologia das plantas, verificadas no porte e no dossel, provocadas pela aplicação de herbicidas são extremamente prejudiciais à fisiologia das culturas,

Tabela 4 - Incidência de luz (lux $\mathrm{cm}^{-2}$ ) nas entrelinhas do algodão, aos 100 dias após a emergência, em função do número de aplicações de amonio-glufosinate isolado e em associação com pyrithiobac-sodium. Chapadão do Sul-MS, 2010

\begin{tabular}{|c|c|c|c|}
\hline \multirow{2}{*}{ Tratamento } & \multicolumn{3}{|c|}{ Número de aplicações } \\
\hline & 1 & 2 & 3 \\
\hline Gluf. $\left(500 \mathrm{~g} \mathrm{ha}^{-1}\right)$ & $11,00 \mathrm{Ab}$ & $10,81 \mathrm{Ab}$ & $11,56 \mathrm{Ab}$ \\
\hline Gluf. + pyri $\left(500+42 \mathrm{~g} \mathrm{ha}^{-1}\right)$ & $13,56 \mathrm{Aab}$ & $14,68 \mathrm{Aa}$ & $13,68 \mathrm{Aab}$ \\
\hline Gluf. + pyri $\left(500+56 \mathrm{~g} \mathrm{ha}^{-1}\right)$ & $14,50 \mathrm{Aa}$ & $13,81 \mathrm{Aab}$ & $15,25 \mathrm{Aa}$ \\
\hline Testemunha capinada & & 11,68 & \\
\hline $\mathrm{CV}(\%)$ & & 20,90 & \\
\hline DMStratamentos & & 3,38 & \\
\hline DMStestemunha & & 3,75 & \\
\hline
\end{tabular}

Gluf. (amonio-glufosinate); pyri. (pyrithiobac-sodium); * Diferem da testemunha pelo teste de Dunnett ( $\leq 0,05)$; Médias seguidas por letras maiúsculas distintas, na linha, e por letras minúsculas, na coluna, diferem pelo teste de Tukey $(\mathrm{p} \leq 0,05)$. pois cada espécie necessita de uma quantidade de luz interceptada para que seu ciclo possa ser desenvolvido naturalmente, garantindo estabilidade na produção (Suganuma et al., 2008). Dessa forma, os danos provocados pela associação entre o amonio-glufosinate e o pyrithiobac-sodium podem acarretar redução na produtividade das plantas submetidas às aplicações dessas misturas.

Com relação aos dados de qualidade de fibra do algodão, não houve efeito da aplicação dos diferentes tratamentos herbicidas sobre o indice Micronaire e a maturidade da fibra (dados não apresentados). A análise dessas características da fibra do algodoeiro é extremamente importante, visto que em trabalho anteriormente descrito na literatura já foi constatado o efeito negativo de aplicações em pós-emergência de herbicidas (Snipes \& Mueler, 1994).

Os resultados referentes ao rendimento de algodão em caroço em função da aplicação dos diferentes tratamentos herbicidas estão apresentados na Tabela 5. Nota-se que a produtividade das plantas de algodoeiro que foram tratadas com amonio-glufosinate isolado (500 $\mathrm{g} \mathrm{ha}^{-1}$ ) não variou em função do número de aplicações feitas em pós-emergência. Esses resultados confirmam os observados em outras variáveis avaliadas, demonstrando que esse cultivar de algodão geneticamente modificado apresentou tolerância a até três aplicações de amonio-glufosinate.

Tabela 5 - Rendimento em arrobas ha- ${ }^{-1}$ de algodão em caroço, em função do número de aplicações de amonio-glufosinate isolado e em associação com pyrithiobac-sodium. Chapadão do Sul-MS, 2010

\begin{tabular}{|l|c|c|c|}
\hline \multirow{2}{*}{ Tratamento } & \multicolumn{3}{|c|}{ Número de aplicações } \\
\cline { 2 - 4 } & 1 & 2 & 3 \\
\hline Gluf. $\left(500 \mathrm{~g} \mathrm{ha}^{-1}\right)$ & $278,34 \mathrm{Aa}$ & $279,57 \mathrm{Aa}$ & $278,47 \mathrm{Aa}$ \\
\hline Gluf. + pyri $\left(500+42 \mathrm{~g} \mathrm{ha}^{-1}\right)$ & $276,76 \mathrm{Aa}$ & $265,45^{*} \mathrm{ABb}$ & $259,81^{*} \mathrm{Bb}$ \\
\hline Gluf. + pyri $\left(500+56 \mathrm{~g} \mathrm{ha}^{-1}\right)$ & $275,58 \mathrm{Aa}$ & $265,08^{*} \mathrm{ABb}$ & $260,06{ }^{*} \mathrm{Bb}$ \\
\hline Testemunha capinada & \multicolumn{3}{|c|}{281,85} \\
\hline CV $(\%)$ & \multicolumn{3}{|c|}{4,25} \\
\hline DMStratamentos & 13,85 \\
\hline DMStestemunha & \multicolumn{3}{|c|}{15,74} \\
\hline
\end{tabular}

Gluf. (amonio-glufosinate); pyri. (pyrithiobac-sodium); * Diferem da testemunha pelo teste de Dunnett ( $\leq \leq 0,05)$; Médias seguidas por letras maiúsculas distintas, na linha, e por letras minúsculas, na coluna, diferem pelo teste de Tukey $(\mathrm{p} \leq 0,05)$. 
Quando se optou pela associação entre os herbicidas amonio-glufosinate e pyrithiobacsodium, verificou-se que uma aplicação apresentou-se como seletiva, independentemente da dose de pyrithiobac-sodium empregada. Isso significa a possibilidade de utilizar um herbicida com efeito residual (pyrithiobac-sodium) no controle de plantas daninhas no algodão transgênico em pós-emergência, sem que haja redução no rendimento dessa cultura (Grichar et al., 2004).

As maiores reduções no rendimento foram verificadas quando se adotaram três aplicações sequenciais da associação entre amonioglufosinate e pyrithiobac-sodium, sendo observada queda na produção próxima a $8 \% \mathrm{em}$ relação à testemunha. Os resultados permitem inferir ainda que o número de aplicações dessa mistura é muito mais determinante na redução da produtividade do que a dose de pyrithiobac-sodium utilizada, constatando-se que entre as doses há menor variação na redução de produtividade, quando comparado ao efeito do número de aplicações.

O algodão transgênico $L^{\circledR}{ }^{\circledR}$ apresentou-se tolerante ao amonio-glufosinate, não sendo verificadas reduções na produtividade das plantas que receberam até $1.500 \mathrm{~g} \mathrm{ha}^{-1}$ desse produto, em três aplicações. A adoção do pyrithiobac-sodium junto ao amonio-glufosinate apresentou-se seletiva ao algodão apenas para uma aplicação em pós-emergência; essa pode representar uma excelente ferramenta no manejo de plantas daninhas nessa cultura, tanto pelo fato do controle residual obtido pelo pyrithiobac-sodium, quanto pela associação de mecanismos de ação distintos, o que amplia o espectro de controle dessa mistura.

\section{LITERATURA CITADA}

ALMEIDA, J. C. V.; LEITE, C. R. F. Eficiência do herbicida pyrithiobac-sodium aplicado em pós-emergência no controle de plantas daninhas na cultura do algodão. Planta Daninha, v. 17, n. 1, p. 131-138, 1999.

BLAIR-KERTH, L. K. et al. Tolerance of transformed cotton to glufosinate. Weed Sci., v. 49, n. 3, p. 375-380, 2001.

BRANSON, J. W. et al. Comparison of trifloxysulfuron and pyrithiobac in glyphosate-resistant and bromoxynil-resistant cotton. Weed Technol., v. 19, n. 2, p. 404-410, 2005.
CAVALIERI, S. D. et al. Tolerância de híbridos de milho ao herbicida isoxaflutole. Planta Daninha, v. 26, n. 4, p. 901-909, 2008.

CONSTANTIN, J. et al. Efeito de subdoses de 2,4-D na produtividade do algodão e suscetibilidade da cultura em função de seu estádio de desenvolvimento. Eng. Agríc., v. 27 , p. 24-29, 2007. (Numero Especial)

DAN, H. A. et al. Seletividade de clomazone isolado ou em mistura para a cultura do algodoeiro. Planta Daninha, v. 29, n. 3, p. 601-607, 2011.

EVERMAN, W. J. et al. Absorption, translocation, and metabolism of glufosinate in transgenic and nontransgenic cotton, palmer amaranth (Amaranthus palmeri), and pitted morningglory (Ipomoea lacunosa). Weed Sci., v. 57, n. 4, p. 357-361, 2009.

EUROPEAN WEED RESEARCH COUNCIL - EWRC. Report of $3^{\text {rd }}$ and $4^{\text {rd }}$ meetings of EWRC. Committee of methods in weed research. Weed Res., v. 4, n. 1, p. 88, 1964.

FREITAS, R. S. et al. Interferência de plantas daninhas na cultura de algodão em sistema de plantio direto. Planta Daninha, v. 20, n. 2, p. 197-205, 2002.

GRICHAR, W. J. et al. Using soil-applied herbicides in combination with glyphosate in a glyphosate-resistant cotton herbicide program. Crop Protec., v. 23, n. 10, p. 1007-1010, 2004.

KOGER, C. H. et al. Effect of residual herbicides used in the last post-directed application on weed control and cotton yield in glyphosate- and glufosinate-resistant cotton. Weed Technol., v. 21, n. 2, p. 378-383, 2007.

LEE, D. R. et al. Glyphosate-resistant soybean interference in glyphosate-resistant cotton. J. Cotton Sci., v. 13, n. 2, p. 178-182, 2009.

MAHAN, J. R. et al. Thermal dependence of bioengineered glufosinate tolerance in cotton. Weed Sci., v. 54, n. 1, p. 1-5, 2006.

MARUR, C. J.; RUANO, O. A reference system for determination of cotton plant development. R. Oleag. Fibrosas, v. 5, n. 2, p.243-7, 2001.

MILLER, D. K. et al. Response of non-glufosinate-resistant cotton to reduced rates of glufosinate. Weed Sci., v. 51, n. 5, p. 781-785, 2003.

MONQUERO, P. A. Plantas transgênicas resistentes aos herbicidas: situação e perspectivas. Bragantia, v. 64, n. 4, p. 517-531, 2005.

SABINO, N. P. et al. Maturidade da fibra de algodão determinada pelo fibrógrafo modelo 430. Bragantia, v. 43, n. 1, p. 87-94, 1980.

Planta Daninha, Viçosa-MG, v. 30, n. 4, p. 853-860, 2012 
SNIPES, C. E.; MUELER, T. C. Influence of fluometuron and MSMA on cotton yield and fruiting characteristics. Weed Sci., v. 42, n. 2, p. 210-215, 1994.

SOUZA, L. S. et al. Seletividade do halosulfuron isolado ou em mistura com glyphosate para culturas anuais.

Planta Daninha, v. 19, n. 3, p. 351-358, 2001.

SUGANUMA, M. S. et al. Comparando metodologias para avaliar a cobertura do dossel e a luminosidade no sub-bosque de um reflorestamento e uma floresta madura. R. Árvore, v. 32 , n. 2 , p. $377-385,2008$.
THOMAS, W. E. et al. Glufosinate does not affect floral morphology and pollen viability in glufosinate-resistant cotton. Weed Technol., v. 18, n. 2, p. 258-262, 2004.

TROXLER, S. C. et al. Clomazone, fomesafen, and bromoxynil systems for bromoxynil-resistant cotton (Gossypium hirsutum). Weed Technol., v. 16, n. 4, p. 838-844, 2002.

WEBSTER, E. P.; SHAW, D. R. Effect of application timing on pyrithiobac-sodium persistence. Weed Sci., v. 45, n. 1, p. 179-182, 1997. 